\title{
Taking Charge: A Proposed Psychological Intervention to Improve Pulmonary Rehabilitation Outcomes for People with COPD
}

This article was published in the following Dove Press journal: International Journal of Chronic Obstructive Pulmonary Disease

\author{
Amanda McNaughton $\mathbb{D}^{1,2}$ \\ William Levack $\left(\mathbb{D}^{3}\right.$ \\ Harry McNaughton ${ }^{2}$ \\ 'Department of Respiratory Medicine, \\ Nottingham University Hospitals NHS \\ Trust, Nottingham, UK; ${ }^{2}$ Medical \\ Research Institute of New Zealand, \\ Wellington, New Zealand; ${ }^{3}$ Department \\ of Medicine, University of Otago, \\ Wellington, New Zealand
}

\begin{abstract}
Pulmonary rehabilitation (PR) is an important, evidence-based treatment that improves outcomes for people with COPD. Individualized exercise programmes aim to improve exercise capacity; self-management education and psychological support are also provided. Translating increased exercise capacity into sustained behavioural change of increased physical activity is difficult. Other unresolved problems with PR programmes include improving uptake, completion, response and sustaining long-term benefit. We offer a different perspective drawn from clinical experience of PR, quantitative and qualitative studies of singing groups for people with COPD, and stroke rehabilitation research that gives psychological factors a more central role in determining outcomes after PR. We discuss Take Charge; a simple but effective psychological intervention promoting self-management - that could be used as part of a PR programme or in situations where PR was declined or unavailable. This may be particularly relevant now when traditional face-to-face group programmes have been disrupted by COVID-19 precautions.
\end{abstract}

Keywords: pulmonary rehabilitation, self-management, self-efficacy, psychological

\section{Introduction}

People living with chronic obstructive pulmonary disease (COPD) commonly carry substantial psychological morbidity along with their chest disease. ${ }^{1,2}$ Furthermore, psychological factors can influence uptake and outcomes of the most effective therapy available for people with COPD - pulmonary rehabilitation (PR). ${ }^{3,4} \mathrm{PR}$ service providers aim to be "patient-centred" in their approach" 5 ,6 and "empower patients" ${ }^{7}$ with both personalized exercise prescription, self-management education and psychological supports. PR audit reports also recommend services be responsive to people from ethnic minorities. ${ }^{8}$ These goals are challenging, especially as face-to-face PR services are likely to remain significantly disrupted in a COVID-19 world. Interventions that help people with COPD self-manage their condition without face-to-face input would be a real advantage.

"Take Charge" is a psychological intervention that potentially meets all these criteria. It is low-cost, requires minimal training and is effective as an adjunct to community rehabilitation for people after acute stroke ${ }^{9}-$ another group with significant psychological comorbidities that affect outcomes. It is also fully personcentred and of proven effectiveness in ethnic minority groups. ${ }^{10}$ With minor modifications from the version used in the stroke trials, Take Charge was used in
Correspondence: Amanda McNaughton Email amanda.mcnaughton@nhs.net
International Journal of Chronic Obstructive Pulmonary Disease 2020:15 2/27-2/33 
a feasibility study for people with COPD following acute exacerbations requiring hospitalization. ${ }^{11}$ The stroke study booklet and training manual are available, free to use (www.mrinz.ac.nz/programmes/stroke).

In this article, we briefly describe the Take Charge intervention and evidence for benefit for people with stroke. We will draw parallels between the evidence concerning stroke rehabilitation and pulmonary rehabilitation, dominated in stroke by physical therapy approaches, and by exercise training in PR and suggest an alternative perspective based on hope, purpose and motivation. Finally, we will propose options for using Take Charge for people with COPD as part of pulmonary rehabilitation.

\section{Learning from the Stroke Rehabilitation Literature}

Although the abrupt onset of stroke requires a different model of rehabilitation from that of pulmonary rehabilitation (PR), PR and stroke rehabilitation (SR) share similarities. Both are supported by overwhelming evidence of effectiveness. ${ }^{12,13}$ Nearly 30 randomized controlled trials (RCTs) confirm a significant reduction in mortality of patients managed in inpatient stroke and stroke rehabilitation units compared to management in general medical wards. ${ }^{13}$ Both PR and SR are "black box" interventions a complex mixture of components with considerable uncertainty as to which parts are critical to successful outcomes. ${ }^{14}$ Finally, both PR and SR aim for behaviour change on the part of participants which is likely influenced by the nature and strength of the relationship between participants and health professionals; an unequivocally "psychological" variable.

Following on from the SR trials, coordinated, therapistled interventions are the recommended approach to stroke rehabilitation. ${ }^{15,16}$ However, large randomized controlled trials aimed at optimizing the timing, dose and specific type of therapy-led intervention (compared to "usual care") have failed to show any additional benefit for patients at the level of independence or quality of life. ${ }^{17}$ This has led some to question the idea that the improved outcomes in the SR trials were solely the result of coordinated therapy. ${ }^{17}$ One alternative hypothesis is that SR has an important psychological component helping to increase motivation in the person with stroke. Most of the SR RCTs were conducted at a time when patients with stroke were managed on general medical wards, with no specific treatments apart from nursing care, and a significant expectation from health professionals, families and patients that this was a life-ending or life-changing event. A key component of stroke rehabilitation units was a shared enthusiasm for managing stroke, mobilizing patients and working with an expectation that there was "life after stroke". ${ }^{18}$ It is possible that patients (and their families) with this hope of a positive future, simply did not die as frequently as those without it. Having hope could substantially affect engagement in physical therapy both in the hospital and at home, enhancing physical recovery. So enhancing personal motivation, in addition to a therapy-led rehabilitation approach, may improve outcomes, where a purely therapy-led approach does not.

Evidence to support this hypothesis comes from two large RCTs involving 572 participants after stroke, testing a psychological intervention aimed at increasing personal motivation. ${ }^{9,10}$ The Take Charge intervention was tested in the early community phase of stroke rehabilitation, $2-16$ weeks after acute stroke, in addition to usual community stroke rehabilitation. One of these studies was with participants from ethnic minority populations. ${ }^{10}$ This very brief intervention (one or two 60 minute sessions in the person's home) uses simple images and prompts, to help the person look beyond their medical condition - in this case, stroke and transform from a "stroke person" into "the real 'me' who happens to have had a stroke" (see Figure 1). ${ }^{9}$ Twelve months after stroke, people exposed to the Take Charge intervention in the Taking Charge after Stroke (TaCAS) trial $^{9}$ were performing significantly more advanced activities of daily living, were less likely to be dependent on another person for help, and reported better quality of life. These are the first trials of a specific stroke rehabilitation intervention that have shown a sustained benefit at the level of independence or quality of life. ${ }^{17}$

"Taking Charge" embraces four fundamental components: a sense of autonomy, a sense of purpose, a sense of competence or mastery and connectedness with others. These components have been extensively studied in the fields of education and psychology as part of Self-Determination Theory. ${ }^{20}$ A facilitator, trained to be completely non-directive, guides the person through the Taking Charge booklet. The first three pages concentrate on sense of purpose, personal identity and hopes for the future, modified as necessary for the specific medical condition of interest (see Figure 2). Further pages consider the issues of importance for the person (eg physical activity, mood, finances, supports, information, disease prevention) with a structure that allows them to break down their hopes for the future into "do-able" steps and identify their key 


\section{What Taking Charge is all about}

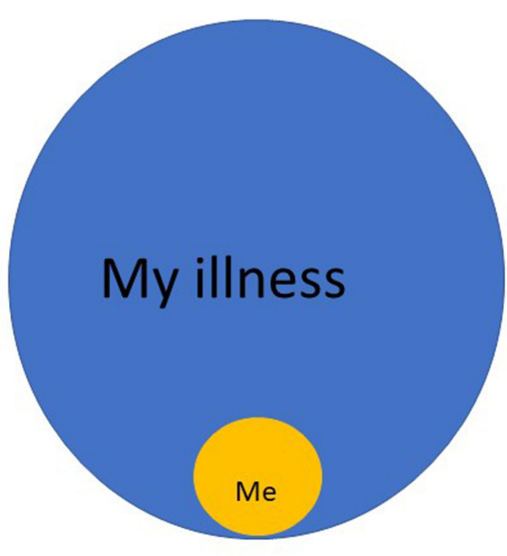

A patient with an illness

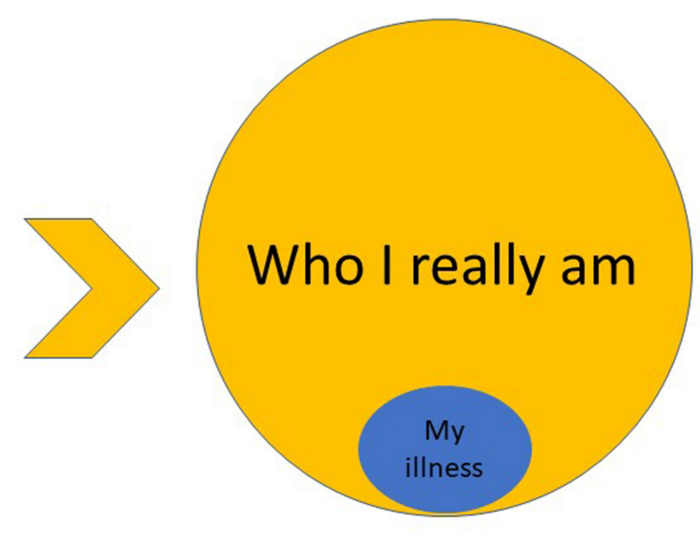

A person who happens to have a medical condition

Figure I Taking Charge: aiming for transformation from a patient defined by their medical condition to the person they really are, who happens to have a medical condition.

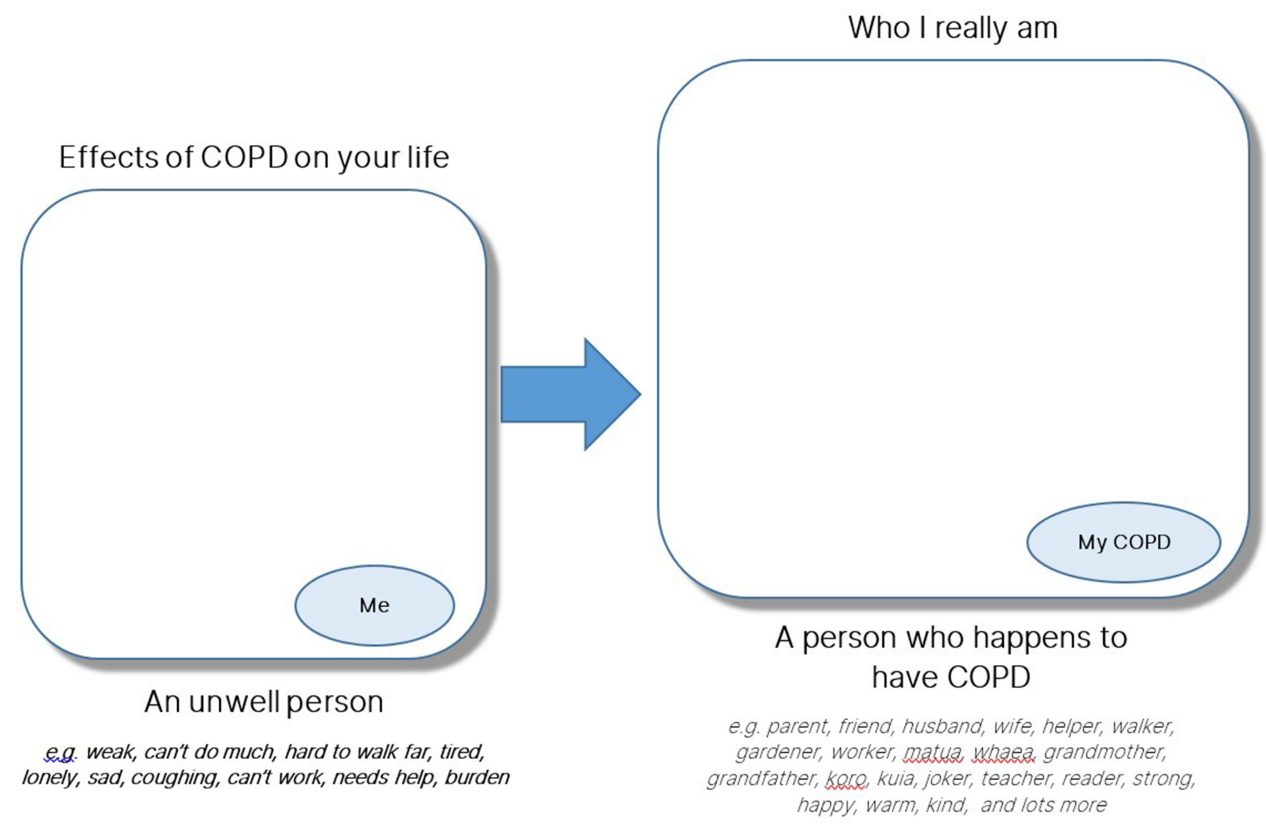

Figure 2 The first page of the Take Charge booklet from a feasibility study for people with exacerbations of COPD requiring hospitalization " showing the translation from the "Taking Charge" concept in Figure I to a specific medical condition, in this case, COPD. The words "matua", "whaea", "koro", and "kuia" are in the Māori language, with English equivalents of parent, mother, male and female elders/grandparents.

support person/people. All ideas come from the person or their family, and the facilitator is trained not to provide 'helpful suggestions' ie this is all about the unique individual and is therefore fully person-centred.

\section{Pulmonary Rehabilitation}

$\mathrm{PR}$ is also a complex intervention. Exercise-training is a core component of PR programmes; guidelines indicate minimum levels of both dose and frequency, tailored to the individual, aiming to increase exercise capacity. ${ }^{21,22}$ There is growing evidence of both the importance of increased physical activity as part of the efficacy of PR, and the substantial independent contribution this makes to health and survival. $^{23-25}$ Translating a personalized exercise programme into the sustained behavioural change of increased physical activity remains a significant challenge 
for PR. This will be potentially more difficult in COVID19 pandemic environments. ${ }^{26}$ Other problems with PR include gross under-utilization of PR (low rates of PR referral, uptake and completion) and considerable heterogeneity in patient responses to PR, as measured by exercise capacity, breathlessness scores, and health-related quality of life. ${ }^{27,28}$ Universal barriers to attendance include: travel and transport, depression, comorbidities, reduced perceived benefit, and socio-economic deprivation; others are patient or place-specific, eg ethnicity. ${ }^{29,30}$ There is evidence that adaptive coping strategies to illhealth affect response to PR. ${ }^{31}$ But although anxiety (36\%) and depression (40\%) are common in patients with COPD, there is no evidence that these conditions impact on rates of completion or response to PR. ${ }^{1,2,32}$

So how can we facilitate behaviour change to increase physical activity? Various groups have studied the use of counselling, coaching and goal setting after PR, generally showing small improvements in physical activity. ${ }^{34,35}$ The barriers and enablers to increasing physical activity for people living with COPD are complex and varied, including physical, environmental and psychosocial factors.

\section{COPD and Pulmonary Rehabilitation: The Psychosocial Dimension}

Living with COPD has social and psychological consequences besides physical constraints. Anxiety, depression, impaired ability to work, problems with sexual function and limitations in social activities impact on wellbeing. An individual's symptoms of breathlessness, and level of disability are complex. The Breathe Oxford group argue that this is beyond the complicated pathophysiology, incorporating prior experiences and expectations as well as the personal perception of body signals. ${ }^{35}$ Most PR programmes include an educational component usually concentrating on self-management, including how to manage breathlessness, medication adherence, inhaler technique, action plans for exacerbations and nutrition, as well as promotion of mental health and facilitation of advanced care plans. Delivered as education, they are by definition health-professional-centred, and in terms of sustained behavioural change, their effectiveness is variable. $^{36,37}$

Outside of PR, many non-pharmacological interventions have shown positive outcomes in terms of mood for people with COPD, including home-based cognitive behavioural therapy, mindfulness, motivational interviewing and singing. ${ }^{38-45}$

Two randomized controlled trials of singing group interventions in COPD report improvements in quality of life and reduction in anxiety, although not in lung function. $^{41,42}$ In our singing group study, there was a significant reduction in the Hospital Anxiety and Depression Scale (HADS) anxiety score between baseline and one year, as well as a significant increase in $6 \mathrm{MWT} .^{43}$ One explanation for the improvement in 6MWT after singing group programmes is that participants are personally motivated - they attempt more themselves (autonomy), have realistic personal goals for improvement (competence/mastery), look forward to the activity and the future (purpose), and feel more socially connected - all components of Take Charge. ${ }^{9}$ In our qualitative study of a COPD singing group, it was clear that social connection in a safe place was a key priority for participants, ${ }^{44}$ confirmed in other studies of PR. ${ }^{32}$ The participants in these studies appreciated the camaraderie of the singing group, with the once-weekly sessions at a community venue being a crucial part of their social schedule. Many of the group overcame significant barriers - transport, weather, intermittent ill-health, exercise restriction - to attend at unexpectedly high rates $(85 \%)$ over a full year. ${ }^{43}$ We think that the social connection component of the singing group, while at the same time doing something that is both challenging and enjoyable, was influential in maintaining the high attendance rate as well as the improved outcomes.

\section{The Importance of Social Connection, Mood and Hope}

The importance of social connection for health and wellbeing is well established. Social isolation, loneliness, and living alone are associated with a $26-32 \%$ increased likelihood of mortality in the general population, ${ }^{46}$ and there is no reason to think the COPD population is any different. ${ }^{1}$ Furthermore, in the general population, social isolation has a significant bidirectional relationship with depression and anxiety. ${ }^{47}$ It makes sense that the same should hold for people with COPD.

Just as people with stroke managed on dedicated stroke rehabilitation wards may be more likely to hope (and believe) in a "life after stroke", we feel one of the key contributors to the consistent benefits of PR, cognitive behavioural therapy and community activities such as COPD singing groups, is that involvement provides 
a person with COPD the hope (and belief) in "life beyond COPD". For people living with progressive dyspnoea and exercise limitation, often accompanied by social isolation, that hope may be the catalyst for engaging in physical and social activities that were previously thought "too hard". 48 Other evidence supports this view. ${ }^{49}$ Arnold and colleagues showed that improvements in quality of life scores after PR were associated with increases in measures of self-efficacy and suggested that "focussing more explicitly on the enhancement of perceptions of personal control in COPD patients may be an important aim of pulmonary rehabilitation". 50

\section{A "Take Charge" Approach for People with COPD?}

There is nothing stroke-specific about Take Charge and early qualitative work showed that patients with a range of medical conditions valued this idea. ${ }^{51}$ Morgan and others have called for a more "person-centred" approach to the person with COPD without being specific about how to go about this. ${ }^{5}$ Take Charge is such a person-centred intervention. A feasibility study using a modified Take Charge intervention for people with a recent exacerbation of COPD requiring hospitalization is complete, and results are awaited. ${ }^{11}$ In that study, there was no problem modifying Take Charge for people with COPD. Building on that work, Take Charge could be tested as an adjunct to standard PR programmes, or for people who decline PR, as a standalone intervention. Meantime, some services wanting to provide a validated tool for person-centred interaction, might choose to incorporate the Take Charge approach into existing PR programmes, at minimal cost. Service configurations have changed dramatically with the advent of COVID-19, both for people with stroke and COPD. Although Take Charge has, so far, only been tested face-to-face, it is possible to deliver the facilitator input by telephone, video link or online chat with the person interacting with a hard copy of the booklet. In a COVID-19 world of limited face-to-face interactions and restrictions on group activities, the built-in social interaction of a regular PR group or singing group will be diminished. There will be a greater onus on the individual with COPD to undertake some or all components of a PR programme on their own. An intervention like Take Charge that explicitly encourages self-management, along with identification of key supporters would be a significant advantage.

\section{Conclusion}

The psychological dimension of PR may be crucial to its effectiveness and enhancing that effect is worthy of further consideration by providers, audit authorities and researchers. A better understanding of this idea and trials of focussed psychosocial interventions may allow a broader range of effective interventions for people with COPD. Our view is we should help the person with COPD get as much out of their life as they want rather than settling for self-management of their condition alone- ie to become "a person who happens to have COPD" rather than remain a "COPD patient". The Take Charge intervention is one option to help make this happen.

\section{Disclosure}

The authors report no conflicts of interest in this work.

\section{References}

1. Willgoss TG, Yohannes AM. Anxiety disorders in patients with COPD: a systematic review. Respir Care. 2013;58(5):858-866. doi:10.4187/respcare.01862

2. Yohannes AM, Alexopoulos GS. Depression and anxiety in patients with COPD. Eur Respir Rev. 2014;23(133):345-349. doi:10.1183/ 09059180.00007813

3. von Leupoldt A, Taube K, Lehmann K, Fritzsche A, Magnussen H. The impact of anxiety and depression on outcomes of pulmonary rehabilitation in patients with COPD. Chest. 2011;140(3):730-736. doi:10.1378/chest.10-2917

4. Spruit MA, Augustin IML, Vanfleteren LE, et al. Differential response to pulmonary rehabilitation in COPD: multidimensional profiling. Eur Respir J. 2015;46(6):1625-1635. doi:10.1183/139930 03.00350-2015

5. Morgan M. Expanding pulmonary rehabilitation capacity. One size won't fit all. Thorax. 2017;72(1):4-5. doi:10.1136/thoraxjnl-2016209345

6. Wouters EFM, Wouters BBRAF, Augustin IML, Franssen FME. Personalized medicine and chronic obstructive pulmonary disease. Curr Opin Pulm Med. 2017;23(3):241-246. doi:10.1097/MCP.00000 00000000377

7. Holland AE. Pulmonary rehabilitation for chronic obstructive pulmonary disease: has it peaked? Respirology. 2019;24(2):103-104. doi: $10.1111 /$ resp. 13447

8. Steiner MC, Lowe D, Beckford K, et al. Socio-economic deprivation and the outcome of pulmonary rehabilitation in England and Wales. Thorax. 2017;72(6):530-537. doi:10.1136/thoraxjnl-2016-209376

9. Fu V, Weatherall M, McPherson K, et al. Taking charge after stroke: a randomized controlled trial of a person-centered, self-directed rehabilitation intervention. Int J Stroke. 2020:174749302091514. doi:10. $1177 / 1747493020915144$

10. Harwood M, Weatherall M, Talemaitoga A, et al. Taking Charge after stroke: promoting self-directed rehabilitation to improve quality of life - a randomized controlled trial. Clin Rehabil. 2011;26(6):4 93-501. doi:10.1177/0269215511426017

11. Levack W. Can a "take charge" intervention reduce incidence of repeat acute exacerbation of chronic obstructive pulmonary disease? A feasibility study. Registered at www.anzctr.org.au ACTRN12617000952347p. 
12. McCarthy B, Casey D, Devane D, Murphy K, Murphy E, Lacasse Y. Pulmonary rehabilitation for chronic obstructive pulmonary disease. Cochrane Database Syst Rev. 2015;2:CD003793. doi:10.1002/ 14651858.CD003793.pub3

13. Langhorne P. Organized inpatient (stroke unit) care for stroke. Cochrane Database Syst Rev. 2013;2013(9). doi:10.1002/14651858. CD000197.pub3

14. DeJong G, Horn SD, Conroy B, Nichols D, Healton EB. Opening the black box of poststroke rehabilitation: stroke rehabilitation patients, processes, and outcomes. Arch Phys Med Rehabil. 2005;86(12):1-7. doi:10.1016/j.apmr.2005.09.003

15. Royal College of Physicians. RCP national clinical guideline for stroke. 2016. Available from: https://www.strokeaudit.org/Guideline/ Guideline-Home.aspx. Accessed June 11, 2020.

16. Royal College of Physicians. National sentinel stroke audit programme. 2019. Available from: https://www.strokeaudit.org/ results/Organisational/National-Organisational.aspx. Accessed June 11, 2020.

17. Winstein C. The ATTEND trial: an alternative explanation with implications for future recovery and rehabilitation clinical trials. Int J Stroke. 2018;13(2):112-116. doi:10.1177/17474930177 43061

18. Baskett J, McNaughton H. Life After Stroke: New Zealand Stroke Guideline. 2nd ed. Wellington: Stroke Foundation of New Zealand; 2003.

19. Langhorne P, Baylan S. Early supported discharge services for people with acute stroke. Cochrane Database Syst Rev. 2017;7. doi:10.1002/ 14651858.CD000443.pub4.

20. Ryan RM, Deci EL. Self-determination theory and the facilitation of intrinsic motivation, social development, and well-being. $\mathrm{Am}$ Psychol. 2001;55:68-78. doi:10.1037/0003-066X.55.1.68

21. McCarthy B, Casey D, Devane D, et al. Pulmonary rehabilitation for chronic obstructive pulmonary disease. Cochrane Database Syst Rev. 2015. doi:10.1002/14651858.CD003793.pub3

22. Bolton CE, Bevan-Smith EF, Blakey JD, et al. British thoracic society guideline on pulmonary rehabilitation in adults. Thorax. 2013;68. doi:10.1136/thoraxjnl-2013-203809

23. Waschki B, Kirsten A, Holz O, et al. Physical activity is the strongest predictor of all-cause mortality in patients with COPD: a prospective cohort study. Chest. 2011;140(2):331-342. doi:10.1378/chest.102521

24. Troosters T, Van Der Molen T, Polkey M, et al. Improving physical activity in COPD: towards a new paradigm. Respir Res. 2013;14 (1):115. doi:10.1186/1465-9921-14-115

25. Spruit MA, Pitta F, McAuley E, et al. Pulmonary rehabilitation and physical activity in patients with chronic obstructive pulmonary disease. Am J Respir Crit Care Med. 2015;192(8):924-933. doi:10.1164/rccm.201505-0929CI

26. Karloh M, Sousa Matias T, Fleig Mayer A. The COVID-19 pandemic confronts the motivation fallacy within pulmonary rehabilitation programs. COPD: J Chronic Obstr Pulm Dis. 2020:1-3. doi:10.10 80/15412555.2020.1790511

27. National COPD Audit Programme: Pulmonary rehabilitation. Time to breathe better British thoracic society, Royal college of physicians, healthcare quality improvement partnership. London; 2015. Available from: https://www.rcplondon.ac.uk/projects/outputs/pulmonaryrehabilitation-time-breathe-better. Accessed June 11, 2020.

28. Pulmonary rehabilitation. An exercise in improvement - combined clinical and organizational audit 2017 RCP London. Available from: https://www.rcplondon.ac.uk/projects/outputs/pulmonaryrehabilitation-exercise-improvement-combined-clinical-andorganisational. Accessed June 11, 2020.

29. Milner SC, Boruff JT, Beaurepaire C, et al. Rate of, and barriers and enablers to, pulmonary rehabilitation referral in COPD: a systematic scoping review. Respir Med. 2018;137:103-114. doi:10.1016/j.rmed. 2018.02.021
30. Levack WM, Jones B, Grainger R, et al. Whakawhanaungatanga: the importance of culturally meaningful connections to improve uptake of pulmonary rehabilitation by Māori with COPD - a qualitative study. Int J Chron Obstruct Pulmon Dis. 2016;11(1):489-501. doi:10.2147/COPD.S97665

31. Russo P, Prinzi G, Kisialou A, et al. Action plans and Coping strategies in elderly COPD patients influence the result of pulmonary rehabilitation: an observational study. Eur J Phys Rehabil Med. 2017. doi:10.23736/s1973-9087.17.04501-4

32. Harrison SL, Greening NJ, Williams JEA, Morgan MDL, Steiner MC, Singh SJ. Have we underestimated the efficacy of pulmonary rehabilitation in improving mood? Respir Med. 2012;106(6):838-844. doi:10.1016/j.rmed.2011.12.003

33. Altenburg WA, ten Hacken NH, Bossenbroek L, et al. Short- and long-term effects of a physical activity counselling programme in COPD: a randomized controlled trial. Respir Med. 2015;109 (1):112-121. doi:10.1016/j.rmed.2014.10.020

34. Bender BG, Depew A, Emmett A, et al. A patient-centered walking program for COPD. Chronic Obstr Pulm Dis. 2016;3(4):769-777. doi:10.15326/jcopdf.3.4.2016.0142

35. Faull OK, Marlow L, Finnegan SL, Pattinson KTS. Chronic breathlessness: re-thinking the symptom. Eur Respir J. 2018;51:1702238. doi:10.1183/13993003.02238-2017

36. Kaptein AA, Fischer MJ, Scharloo M. Self-management in patients with COPD: theoretical context, content, outcomes, and integration into clinical care. Int J Chron Obstruct Pulmon Dis. 2014;9:907-917. doi:10.2147/COPD.S49622

37. Zwerink M, Brusse-Keizer M, van der Valk PD, et al. Self management for patients with chronic obstructive pulmonary disease. Cochrane Database Syst Rev. 2014;3.

38. Bove DG, Lomborg K, Jensen AK, Overgaard D, Lindhardt B, Midtgaard J. Efficacy of a minimal home-based psychoeducative intervention in patients with advanced COPD: a randomized controlled trial. Respir Med. 2016;121:109-116. doi:10.1016/j.rmed.20 16.11.009

39. Farver-Vestergaard I, O'Toole MS, O'Connor M, et al. Mindfulnessbased cognitive therapy in COPD: a cluster randomized controlled trial. Eur Respir J. 2018;51:1702082. doi:10.1183/13993003.02082-2017

40. Benzo RP. Mindfulness and Motivational Interviewing: two candidate methods for promoting self-management. Chron Respir Dis. 2013;10 (3):175-182. doi:10.1177/1479972313497372

41. Lord VM, Cave P, Hume VJ, et al. Singing teaching as a therapy for chronic respiratory disease-a randomized controlled trial and qualitative evaluation. BMC Pulm Med. 2010;10. doi:10.1186/1471-2466-10-41

42. Lord VM, Hume VJ, Kelly JL, et al. Singing classes for chronic obstructive pulmonary disease: a randomized controlled trial. $B M C$ Pulm Med. 2012;12. doi:10.1186/1471-2466-12-69

43. McNaughton A, Weatherall M, Williams M, et al. Sing your lungs out-a community singing group for chronic obstructive pulmonary disease: a 1-year pilot study. BMJ Open. 2017;7(1):e014151. doi:10.1136/bmjopen-2016-014151

44. McNaughton A, Aldington S, Williams G, Levack WMM. Sing your lungs out: a qualitative study of a community singing group for people with chronic obstructive pulmonary disease (COPD). BMJ Open. 2016;6(9):e012521. doi:10.1136/bmjopen-2016-012521

45. Mcnamara RJ, Epsley C, Coren E, Mckeough ZJ. Singing for adults with chronic obstructive pulmonary disease (COPD). Cochrane Database Syst Rev. 2017;12. doi:10.1002/14651858.CD012296.pub2

46. Holt-Lunstad J, Smith TB, Baker M, et al. Loneliness and social isolation as risk factors for mortality: a meta-analytic review. Perspect Psychol Sci. 2015;10(2):227-237. doi:10.1177/1745691614568352

47. Santini ZI, Jose PE, York Cornwell E, et al. Social disconnectedness, perceived isolation, and symptoms of depression and anxiety among older Americans (NSHAP): a longitudinal mediation analysis. Lancet Public Health. 2020;5(1):e62-e70. doi:10.1016/S2468-2667(19)30 230-0 
48. Williams V, Bruton A, Ellis-Hill C, McPherson K. What really matters to patients living with chronic obstructive pulmonary disease? An exploratory study. Chron Respir Dis. 2007;4(2):77-85. doi:10.1177/1479972307078482

49. Selzler AM, Moore V, Habash R, et al. The relationship between self-efficacy, functional exercise capacity and physical activity in people with COPD: a systematic review and meta-analyses. COPD J Chronic Obstr Pulm Dis. 2020;17(4):452-461. doi:10.1080/15412 555.2020 .1782866
50. Arnold R, Ranchor AV, Koëter GH, et al. Changes in personal control as a predictor of quality of life after pulmonary rehabilitation. Patient Educ Couns. 2006;61(1):99-108. doi:10.1016/j.pec.2005.02.015

51. McPherson KM, Brander P, Taylor WJ, McNaughton HK. Consequences of stroke, arthritis and chronic pain - are there important similarities? Disabil Rehabil. 2004;26(16):988-999. doi:10.1080/ 09638280410001702414

\section{Publish your work in this journal}

The International Journal of COPD is an international, peer-reviewed journal of therapeutics and pharmacology focusing on concise rapid reporting of clinical studies and reviews in COPD. Special focus is given to the pathophysiological processes underlying the disease, intervention programs, patient focused education, and self management protocols. This journal is indexed on PubMed Central, MedLine and CAS. The manuscript management system is completely online and includes a very quick and fair peer-review system, which is all easy to use. Visit http://www.dovepress.com/testimonials.php to read real quotes from published authors.

Submit your manuscript here: https://www.dovepress.com/international-journal-of-chronic-obstructive-pulmonary-disease-journal 